\title{
Omayra: reflexões sobre o rosto, uma fotografia e suas políticas ${ }^{1}$
}

\author{
Angela Cristina Salgueiro Marques \\ Angie Biondi
}

Resumo: O presente artigo parte da fotografia da menina Omayra Sanchez para refletir acerca de como a imagem fotojornalística pode conferir rosto a um indivíduo, tornando-o sujeito pelo nosso olhar. O rosto encarnado na superfície fotográfica permite o aparecer do estranho, fazendo emergir o lugar da comunicação, da reciprocidade. A política da imagem pode, ao mesmo tempo, revelar um "em comum", um incomum e uma parte de outrem que não se deixa apreender, que não consegue traduzir-se em comunicação. Por meio da elaboração de três seções interligadas, buscamos entender como esta imagem nos apresenta o lugar do outro que se transforma na promessa do meu próprio lugar, assumindo um caráter estético, ético e político. Abertura, passagem e interdição compõem os movimentos do processo intermitente de produção de gestos e olhares subjetivantes.

Palavras-chave: fotojornalismo; imagem; política; rosto.

Abstract: Omayra: reflections on face, photography and their political issues - This article proposes some reflections on the girl Omayra Sanchez's photograph to reveal how photojournalistic image can constitute someone's face by making it subject to our glance. The printed face on the photographic surface makes the stranger appear and brings out the place of communication and reciprocity. At the same time, the politics of image can reveal a "being common", or an uncommon, or a piece of someone else that is not easy to apprehend, not translatable into communication. In a threefold session, this article seeks to understand how that image shows us the other's place transformed by the promise of my place, assuming an aesthetic, ethical, and political aspect. Opening, passage and interdiction compose the movements of the intermittent, productive process of subjectifying glances and gestures.

Keywords: photojournalism; image; politics; face.

\section{Introdução}

No ano de 1985, a menina colombiana de 13 anos, Omayra Sánchez Garzón, ficou conhecida no mundo inteiro por uma imagem realizada pelo fotojornalista francês

1 Este trabalho foi realizado com o apoio do CNPq. 
Frank Fournier (vencedor, no mesmo ano, do World Press Photo of the Year). Omayra ficou presa durante sessenta horas sob os escombros de sua casa após a erupção do vulcão Nevado del Ruiz. Com o corpo mergulhado em água e as pernas dobradas e esmagadas sob o que havia sido o telhado da casa onde morava, Omayra contou com os esforços de socorristas voluntários e com o apoio de jornalistas, os quais, por mais que quisessem, não conseguiram salvá-la.

O rosto e o olhar de Omayra, capturados poucos momentos antes de seu falecimento, nos levou, em um primeiro momento, a refletir acerca de uma política suscitada por essa imagem, mais precisamente, acerca de sua potência convocadora e ética. Sabemos, de acordo com a reflexão proposta por Jacques Rancière $(2007,2012)$, que a política das imagens não pode ser identificada a partir de uma instrução fornecida, por elas, para o acionamento de sentimentos morais como a indignação, o assombro, a contestação da injustiça, o compadecimento ou mesmo o horror. A imagem não deve ser, segundo ele, reduzida a um texto que busque esclarecer causas e efeitos das injustiças. Assim, a política das imagens não está no conteúdo representativo por elas expresso e nem se concretiza como uma instrução para olhar para o mundo e transformá-lo através da tomada de consciência de formas opressoras e padecimentos.

Acreditamos que a potência política está tanto nas imagens (materialidade sígnica) quanto nas relações e operações que as definem, uma vez que "a imagem não é simplesmente o visível. É o dispositivo por meio do qual esse visível é capturado" (idem, 2007 , p.199). Essas operações influenciam a caracterização política do que vemos. São as relações que definem as imagens, isto é, as relações que se estabelecem dentro e fora do âmbito visual, que pré-configuram enunciados, que montam e desmontam relações entre o visível e o invisível, o dizível e o silenciável (ibidem).

Rancière (ibidem) deixa claro, portanto, que uma investigação acerca da política das imagens deve procurar observar o modo como os corpos representados indicam possibilidades de resistência, subversões e reinvenções dos modelos de captura aos quais estão submetidos rotineiramente. Sob esse aspecto, é possível afirmar que a potência política observada a partir da imagem de Omayra se encontra nas operações de visibilidade que configuram seu rosto no retrato.

O rosto nem sempre se deixa capturar por meio de conceitos ou imagens. De acordo com Lévinas (2010), o rosto que dá acesso ao mundo do outro não é passível de ser escrutinado e resiste infinitamente a nossos esforços de aproximação e apropriação. Em uma abordagem singular, Lévinas revela o rosto como potência de contato com a alteridade, em uma dimensão ética que requer o acolhimento do outro. O rosto marca, nessa perspectiva, uma relação de abertura para outro, uma forma de diálogo em que um não possui o outro, tampouco se reconhece nele. O rosto expressa o fato de que o outro não é uma variação do eu e não pode ser capturado ou assimilado por conceitos. Ele pode nos colocar diante de uma alteridade que nos interpela, que sofre, que deseja e que nos convida a nos afastarmos de nós mesmos. 
Lévinas (ibidem) não percebe o rosto como imagem representativa do sujeito, pelo contrário, deseja mostrar sua "aparição": por isso ele afirma que o rosto possui uma visibilidade que só é apreendida pelo olhar, na qual o outro que me olha é aquele que me revela. O olhar é parte integrante da manifestação e aparição de outrem. Nesse sentido, a emergência do rosto como imagem fixa nas fotografias nos convida a perscrutar, a olhar o rosto e o corpo do outro, revelando a imagem como importante suporte de acesso ao outro e à sua aparência. Por isso, imagens do rosto podem ser pensadas como o lugar do outro que se transforma na promessa do meu próprio lugar, assumindo caráter estético, ético e político (AGAMBEN, 2000; MARQUES, 2014).

Nas seções que se seguem, tentamos evidenciar como a imagem de Omayra nos convoca e nos sensibiliza de modo a presentificar e a apresentar dois tipos de sofrimento: o primeiro, que deriva da catástrofe, o segundo, que estabelece um vetor de implicação do espectador na interpretação da imagem, proporcionando modos de afeto e de aproximação com a alteridade. Argumentamos que o sofrimento comunicado por esta imagem figura como uma forma de experiência com o Outro. Seu rosto é o que me afasta de mim e me conduz ao labirinto da alteridade. Esse rosto não é propriamente a face humana, mas um vestígio da presença de um Outro que, por mais que esteja próximo, mantém-se à distância. Por isso, ele é comunicação e linguagem, aparição e desaparição, possibilidade e impossibilidade de alcançar o Outro em sua infinitude.

\section{Abertura: experiências do ver no fotojornalismo}

O reconhecimento dos códigos que marcaram convencionalidades no modo de ver fotografias de jornalismo apenas como registro dos fatos ocorridos, pois baseados em um quadro de referências dado ao longo do tempo, não é suficiente porque não está isolado ou independente da situação concreta que lhe caracteriza: a experiência do ver. Em certa direção de análise, muito recorrente nos estudos da comunicação, em que se problematiza algum produto da mídia, colocaríamos, quase impulsivamente, um tema sob a regência do gênero discursivo e midiático, a fim de indicar quais as estratégias visuais seriam utilizadas e viriam lhe emoldurar. Assim, um tema, qualquer que fosse, atenderia a uma questão de gênero ou formato em que os personagens seriam "capturados" em seus eventos e oferecidos em um produto - a fotografia de imprensa -, a fim de orientar o espectador em seus modos de apreensão.

Sob essa perspectiva, o fotojornalismo estaria comprometido com uma dupla função. Por um lado, seu trabalho seria o de encontrar formas de controlar a manifestação do evento que informa o tema em suas ocorrências cotidianas, colocando-o sob uma espécie de apaziguamento visual adequado aos seus vínculos institucionais e discursivos. Por outro lado, esta mesma produção visual deveria atender à função de constranger os espectadores no contato com as fotos. Haveria uma ênfase na dimensão determinista 
do gênero jornalístico que acabaria restringindo suas operações ao quadro de uma demarcação condicionada dos lugares do fotografado, da fotografia e do espectador.

Neste texto, o objeto fotográfico interessa como ponto de inflexão, articulado no entrecruzamento de seus aspectos, sejam culturais, indiciais, ou expressivos. Mesmo de cariz jornalístico, afeitas aos protocolos de documentaridade, desde o período moderno, as fotografias de imprensa têm apresentado facetas diferenciadas dos seus registros que permitem notar modos peculiares na elaboração de suas formas visuais, tanto ao nível da representação dos fotografados, capturados nas mais diversas situações do cotidiano, quanto nas relações espectatoriais que estabelecem.

Desse modo, é preciso considerar que as fotografias funcionam em uma espécie de duplo regime: são tanto objetos culturais, atravessados por códigos e convenções sociais, demarcados historicamente, quanto objetos sígnicos em seu aspecto referencial ou indicial do fato. O funcionamento das imagens opera na injunção desses pontos, produzindo movimentos diferenciados de aproximação, intensificação, afastamento ou contraste que promovem relações distintas com o espectador. Considerar esse modo de funcionamento das fotografias implica um movimento reflexivo para desmobilizar, de imediato, o argumento da objetividade fotográfica que possa reverberar ainda nos estudos sobre o fotojornalismo como matriz única de análise. Se adotássemos exclusivamente essa premissa, tão cara à tradição dos estudos sobre fotografia jornalística, o trabalho com as imagens se reduziria apenas ao mapeamento e identificação de personagens e seus fatos.

Por mais que não seja nosso foco resgatar toda tradição teórica, não é possível descartar, de imediato, que o investimento de pesquisa em torno da técnica fotográfica ensinou que seu produto deve ser tomado como impressão de um referente. Mas é exatamente esse aspecto que aparece, ora tensionado, ora revigorado, em muitas das imagens que compõem o corpus em questão. Por vezes, o que se evidencia na imagem é seu caráter atestador do fato, em outras, apenas um aspecto do fato é exibido e não se torna evidente sequer qual evento é reportado.

Diante de tais deslocamentos observados no fotojornalismo, a investigação requer o esforço de compreender a fotografia na constituição da visibilidade de um tema através dos arranjos e relações que se promovem entre os elementos, na fotografia e através dela, para além da mera sistematização descritiva e referencial dos acontecimentos. O fotojornalismo, como um dos campos ativos no qual se engendra a experiência do ver, solicita uma compreensão mais ampla das relações produzidas entre a fotografia, o fotografado e o espectador.

Pensamos que a experiência de ver fotografias, uma das práticas mais cotidianas deste tempo, é sempre da ordem de um contato, de um encontro com as imagens em uma situação material e concreta. Ver fotografias do jornalismo apresenta uma complexidade própria por conta das implicações convencionais dos seus códigos culturais, indiciais, mas também plásticos, expressivos e sensíveis, que se entrelaçam às referências do espectador, produzindo, portanto, experiências. 
Defrontar-se com fotografias que mobilizam temas como catástrofes, violências, doenças, acidentes, penúria e toda ordem de designação do sofrimento humano pode articular o conjunto desses elementos, de modo que, em uma situação mais corriqueira, seja possível acionar deslocamentos e desvios que potencializem, para além da função referencial ou de índice, uma interação de natureza afetiva, produzindo uma experiência entendida, aqui, como uma interação.

Uma experiência mediada, como esta que pode ser efetuada através do fotojornalismo, é uma experiência inserida no solo sócio-histórico, mas que também se efetiva como forma de compartilhamento. É através desse sofrimento cotidianamente noticiado, fotografado, visto e revisto, contaminado pelas impurezas que se aderiram ao longo do percurso informativo, institucional, cultural e do consumo que ocorrem pontos de encontro com o espectador.

A experiência do sofrimento, mediada pelo fotojornalismo, não deve ser subjugada de antemão nem ao condicionamento técnico de captura, nem ao condicionamento institucional ou do mercado, que exerceria, com plenitude, o trabalho de limitação das imagens bem como o despoder dos sujeitos. Pensar as relações entre fotografias e sujeitos solicita considerar uma perspectiva relacional.

As preocupações em definir qual tipo de experiência, afinal, se poderia acionar, mobilizar, convocar, enfim, notar, no campo das imagens fotojornalísticas, comparecem com mais força e discussão nos últimos anos, seguindo uma afirmação de "crise dos usos" (POIVERT, 2010), que admite certo esgotamento de protocolos definidos, há muito, por sua legitimidade mediatizada e, ao mesmo tempo, por sua pretensão histórica calcada na definição de certa singularidade dos acontecimentos.

A aliança entre uso de protocolos para uma moral testemunhal apenas ratifica a associação por demais estreita entre o lugar da fotografia jornalística e o lugar da experiência que ela delimitaria e/ou inscreveria previamente. A definição dos pares (lugar da fotografia-lugar da experiência), aliás, constitui um modelo primordial que retira, tanto da imagem quanto do espectador, qualquer possibilidade de agenciamento ou negociação, para colocar o reconhecimento como único aspecto definidor da relação entre ambos. A crise, se existe, afirma-se na medida em que está circunscrita aos campos definidores dos usos que precarizam as relações entre imagens e sujeitos.

A figura da "crise" na fotografia jornalística que nos interessa não se detém no deslocamento de certa imagem aos modelos do gênero convencionados na estrutura imagética para a finalidade espectatorial, mas emerge porque se instaura através de uma efetiva ruptura promovida pelo aspecto sensível. Não é o uso por desgaste de uma tradição da imagem jornalística (iconográfica, discursiva, estilística) e que não encontra mais fôlego na sociedade (na cultura e nas demandas) contemporânea, mas porque revolve, irrompe, fratura, enfim, a lógica do reconhecimento e porque se instaura no nível dos afetos, da mobilização constituinte do olhar. Portanto, a experiência do ver fotografias, mesmo no jornalismo, não prescinde nem da imagem e nem do sujeito, 
mas observa-os em relação, pois não se efetiva por um aspecto exterior a ela e que deriva de funções, objetivos, estratégias, causas ou efeitos próprios de uma época, estes, sim, fadados à substituição.

\section{Passagem: a convocação no olhar do estranho}

Um tipo de convocação peculiar entra em jogo na foto de Omayra, mas em nada suscita comoção, piedade ou solidariedade como aspectos típicos de uma moral testemunhal. Somos convocados ao retorno deste olhar que sustenta o limite entre vida e morte, o humano e o monstruoso.

Seus olhos surgem completamente negros, rodeados por manchas escuras, e suas mãos manchadas exibem os dedos esbranquiçados e encarquilhados com uma pele de aspecto rugoso em nada semelhante à textura da pele humana. Outros elementos também se relacionam às mãos e aos olhos compondo ainda mais a intensidade estranha que adquire esta personagem na fotografia.

Ela submerge ou surge deste caldo lodoso? E de que se trata esta viscosidade na qual parece habitar? Nenhum movimento de contração é perceptível em seu rosto como se o ambiente lhe fosse desagradável ou incômodo. Nenhum esforço do corpo é notado como iminente ação de saída deste visco, tampouco parece afundar nele; ela não se debate e nem se recolhe neste lago pantanoso.

De seus olhos quase nada se vê de um órgão humano, pois todo o globo ocular é tomado por uma coloração muito escura, quase preta, que esconde as partes típicas do órgão, a íris e a esclera, o que acentua a estranha sensação de sermos encarados por olhos de um animal ou de um monstro. Mesmo a possibilidade de notar certa delicadeza do rosto da personagem, o detalhe de artigos femininos adornando as orelhas ou o semblante de uma garota jovem, não consegue suprimir a força estranha com que seu olhar nos confronta.

Trata-se de um olhar eloquente que inquire, interpela, afeta, mas sem a aparente mobilização de qualquer recurso emocional, senão a insistência perturbadora que desloca o espectador de uma posição geral, do seu lugar inscrito, para ser o sujeito singular deste olhar. Sem as muletas de uma narrativa que facilite a reconstrução minuciosa do porquê, como, onde, quando, por quem ou de que modo sua personagem chegou a este estado, em primeira instância, ela se deixa mostrar, exibir, fotografar, se fazer imagem, se põe diante de um igualmente outro, sem que os porquês se interponham neste breve diálogo silencioso do olhar. É um diálogo sem linguagem, sem um propósito, mas como suspensão; é um encontro levado pelo único movimento do percurso do olhar que passeia por entre os detalhes desta face em toda sua estranheza.

Trata-se do compartilhamento de uma intimidade breve, precária e fugaz. Nada mais íntimo, neste encontro, que o peculiar modo de presença instaurado pela convocação do olhar. É ele que interpela e, ao mesmo tempo, se oferece em uma sensibilidade diferenciada 
das fotografias protocolares, tão bem inscritas na tradição do fotojornalismo, para se pôr como uma pequena variação da percepção diante do que se mostra estranho ou intolerável.

Didi-Huberman (1998), ao retomar Freud, para explicar o que se passa na inquietante experiência de ver o que é estranho, indica que:

é a desorientação, experiência na qual não sabemos mais exatamente o que está diante de nós e o que não está, ou então se o lugar para onde nos dirigimos já não é aquilo dentro do qual seríamos prisioneiros. Propriamente falando, o estranhamente inquietante seria algo em que, por assim dizer, nos vemos totalmente desorientados (ibidem, 1998, p. 231).

Unheimlich, o estranho, é uma concepção formulada por Freud (apud DIDIHUBERMAN, 1998) e que indica uma abertura do limite entre o estranho e o familiar, pois diz daquilo que perturba o que deveria ser a harmonia entre dois. O que se põe é uma ruptura daquilo que deveria ser uno, pois encarar o estranho é permanecer à orla, na tensão, desorientado diante de cada signo que exige um reconhecimento; é estar entre um diante e um dentro.

Mas estas duas estão ligadas ontologicamente, pois nossa desorientação do olhar implica ao mesmo tempo ser dilacerados pelo outro e ser dilacerados por nós mesmos, dentro de nós mesmos. Perdemos algo, somos ameaçados pela ausência. (DIDI-HUBERMAN, 1998, p. 231).

Só estranhamos aquilo que já conhecemos, segundo Freud (apud DIDI-HUBERMAN, 1998). Precipitar-se e lançar-se ao desconhecido do outro, tal qual ele seja, é experimentar seu limiar, atravessá-lo. "E nessa différance se mantém, se suspende todo o nosso olhar, entre o desejo de passar, de atingir o alvo e o luto interminável de, antecipadamente, saber jamais poder atingir o alvo" (DIDI-HURBERMAN, 1998, p.232). Esta desconfortável postura define toda experiência deste olhar recíproco. Todo o discurso identitário possível é traído pelo olhar de Omayra.

Respondemos à convocação deste olhar, participamos, ainda que desconfortáveis, do movimento que ele provoca. Coabitamos, mesmo por um breve momento, no suplício que assalta este corpo paralisado e petrificado por atingir o último fio do limite da vida assolado pela morte. Por esse olhar, coexistimos no entretempo em que uma vida individual enfrenta a morte universal.

Assim, deslocada das mobilizações morais próprias ao gênero, nesta fotografia não há lugar para compaixão e nem solidariedade. Neste olhar e neste corpo não há possibilidade de projeção, mas enfrentamento de corpos, já que não podemos nos colocar no lugar deles, mas apenas através deles é que experimentamos, não algo da ordem de um suplício, mas a fria sensação da presença de morte. Esta imagem, enfim, põe em xeque a posição por demais confortável a que se acostumou o espectador no fotojornalismo. Ela rompe com 
certa estrutura que conforma uma espécie de expectativa do ver coligada a um repertório visual a que se recorre para apresentar sofredores e seus tormentos.

Aqui, o fotojornalismo não pode apenas ser tomado como mera exibição dos fatos cotidianos, da vida real de um sujeito ordinário, pois o testemunho o qual experimentamos é proveniente de outra ordem de acontecimento. A natureza da imagem põe sua força de relato na relação pragmática do binômio ver/ser visto. Não é simplesmente por mostrar o real como ele é, nem como outra realidade fictícia que o sobrepõe, mas por apresentar um real que atravessa a imagem, que se deixou como vestígio de seu acontecimento. Há, portanto, duas ordens de sofrimento em jogo: uma que representa o evento real sob o qual se abateu a personagem, e outra que se manifesta na relação atual do ver, dada entre imagem e espectador, entre o que afeta e é afetado.

Como afirma Picado (2009), ao ser rendido pelo olhar do rosto fotografado, o espectador se transformaria numa espécie de participante vicário da situação instaurada pelo arranjo da fisionomia na imagem. Essa dinâmica rompe o caráter extensivo no qual o espectador apenas testemunha um sofrimento para, com ele, dialetizar; como aquele que toma um lugar para si, aquele que foi "deslocado de certa ordem contemplativa para ser sujeito ativo, lugar político de um gesto onde o contato opera na partilha dos olhares" (MONDZAIN, 2009, p. 23). Nessa captura em que jogamos o que você vê em mim que eu não vejo? (KHEL, 1988, p. 411), há um outro sofrimento que se põe em cena diante da dificuldade em perceber a própria imagem. Quem sou eu questiona o código que o outro possuiria para decifrá-lo. Daí o olhar ser traduzido, no estranho, pela perplexidade, onde se procura reconhecer o domínio de si através do outro.

Lógica do espelho: o externo enuncia eu te vejo assim, revela-o, em boa medida. Nesta dialética do olhar, ver e ser visto, o que vemos e o que nos olha, como propôs Didi-Huberman (1998), compõe a mesma face da ação do olhar. "O que reflete de mim nestes olhos que me veem e pelos quais eu me vejo?". Unheimlich funciona por uma lógica contrária: é o desejo avesso daquele nutrido pelo olhar narcísico, maravilhado por vislumbrar a perfeição. O olhar que se seduz, no estranho, frustra e castra o ideal uno porque interrompe a união que se promoveria entre eu e outro - fusão do desejo ilusório do retorno ao um e ao mesmo.

Diante desse modo especial de presença das fisionomias, um rosto se fragmenta, não consegue suportar uma identidade, rompe com a finalidade única de um exemplar e amplia seu horizonte de possibilidade na medida em que exibe sua constituição das possibilidades, das múltiplas faces, enfim, da singularidade qualquer. Essas pequenas variações, que podem parecer ínfimas diante dos massivos projetos identitários perpetuados pela mídia, atuam por intensidade expressiva. Podemos dizer que uma micropolítica da resistência pode, enfim, surgir, reinventando os regimes de enunciação na imagem, pela imagem, extravasando o gênero e dispersando o projeto serial das identidades. 
O estranho abre uma brecha, oferece uma via. Mas, se não há desejo sustentável na imagem, o que fazer com este outro, que nos chega trazido pela imagem? "Deixemos que as imagens atrozes nos persigam", declara Susan Sontag (2003, p. 95).

Não teria sido este o maior feito de Perseu? Ter cortado a cabeça de Medusa, vencido o medo e olhado seu reflexo - imagem - no escudo? Se o mito de Medusa recorda que o horror é para nós uma fonte de impotência que aniquila e petrifica o sujeito olhante, a redenção viria, paradoxalmente, de conseguir manter o estranho sem torná-lo um, resistindo ao desejo de fazê-lo um, o que, fatalmente, nos faria sucumbir à morte da fusão narcísica (princípio da imagem).

Devemos saber "manejar o escudo, a imagem-escudo" (DIDI-HUBERMAN, 1998, p. 225). A lição de Perseu é a luta incessante do ethos contra os poderes de uma imagem que, se apenas sedutora, se revelaria monstro paralisante, mas, sobretudo, devorador. O jogo sedutor de uma imagem deixa de escravizar e passa à liberdade quando se redime o olhar do simples jogo, quando se atravessa a fronteira, quando se precipita, na própria imagem de si e do outro. Se a imagem do estranho pode nos propor tal experiência, como afirmava Freud revisado por Didi-Huberman (1998, p. 222), é pela certeza de que a inquietude do olhar o outro e se olhar no outro deixou, na imagem, o seu resíduo, pois "nela, desdobra-se ainda a bela energia de Perseu".

\section{Interdição: o rosto e a política da imagem}

"O rosto é o que nos proíbe de matar", afirma Emmanuel Lévinas (1982). Em seu conjunto de ensaios sobre a alteridade, Lévinas (1982; 2004) denuncia a dimensão da cultura, do saber e da arte como campos de domínio em que o inumano é um elemento isolável e absorvido pelo humano de modo que se apresenta a tarefa de tudo reunir sob o Uno, ao Todo. Esta tem sido a lógica que o autor aponta como a tradição da cultura ocidental que se mostra, ainda hoje, dependente do mesmo Logos, devoto do ideal neoplatônico.

Diante dessa primeira denúncia é que Lévinas lança questões que exigem o reposicionamento tanto de um campo do saber como do pensamento acerca das relações que se desdobram sob tal perspectiva. Na recusa de uma redução do Outro ao mesmo é que se poderia restituir ao Outro seu caráter absoluto e irredutível de modo a não apenas mantê-lo em sua integridade, mas vislumbrá-lo em sua natureza autônoma. A relação com outrem não é relação se há privação do Outro. O Outro não se reduz e nem se aparenta ao Mesmo do eu humano. Assumida tal perspectiva, uma questão se torna urgente: como é possível vislumbrar o Outro em sua alteridade? É aqui que se descortina uma das considerações mais intensas do seu pensamento para refletir o sofrimento como uma forma de experiência com o Outro.

Em sua integridade e separação absoluta, o Outro é refratário a toda síntese (LÉVINAS, 2004, p. 236). Portanto, na impossibilidade de apropriar-se dele, o Outro só 
pode ser vislumbrado na experiência da ética que "consiste em experimentar-se através da transcendência da ideia de infinito que é o outro. Trata-se, por conseguinte, da experiência de assimetria significada na epifania da face do outro" (HADDOCK-LOBO, 2010, p.76). O rosto é a figura que consiste em um desvelamento que é, ao mesmo tempo, revelação de infinitude da vida e do homem que continuará apesar do eu. Contudo, o rosto é sem face; não assume e nem se confunde com qualquer identidade ou semelhança.

"Quando se vê um nariz, os olhos, uma testa, um queixo e se o pode descrever, é que nos voltamos para outrem como para um objecto. A melhor maneira de encontrar outrem é nem sequer atentar na cor dos olhos!" (LÉVINAS, 2010, p. 67). Ele não apresenta qualquer forma plástica. Lévinas (ibidem) não rechaça a participação da percepção na constatação da presença de outrem, o que refuta é encerrá-lo como propriedade cultural, limitá-lo a um conteúdo ou mesmo a um personagem em dado contexto. O rosto, para Lévinas, constitui um limite e também um acesso deste outrem, portanto, é seu limiar.

O encontro com outrem consiste na relação ética que é já experiência, pois não se trata de apropriação, assimilação ou outra operação identitária. O rosto só pode existir para o eu na medida de seu vislumbre. O rosto aparece, então, com toda proximidade, nudez e carência da expressão como tal. Ele não é manifestação, mas "exposição à queima-roupa"; presença pura que se interpõe, interpela, evoca e também interdita o eu ao espaço resguardado deste Outro.

Como paradoxo, Lévinas (2004) aponta o rosto como lugar da vulnerabilidade, da carência, do que está nu, despojado de tudo e exposto. Por isso mesmo, solicita o retorno, apela e convoca à relação, mas também, em seu estado vulnerável, incita à violência, ao assassinato, à tentação última de negligenciá-lo até o fim e levá-lo ao isolamento e à morte. No entanto, é através desse paradoxo que se revela que o rosto solicita responsabilidade.

Seguindo este pensamento, o sofrimento do outro que nos interpela consiste em um irrecusável chamamento, pois o sofrer é um padecer em estado puro. A concepção do sofrimento para Lévinas (2004) não incide sobre uma espécie de excesso da sensação de dor, mas sobre uma aberração do próprio sentido. O sofrimento não cabe no pensamento, pois é o absurdo revelado; "não é somente uma consciência de uma rejeição, ou sintoma de rejeição, mas a própria rejeição: consciência ao avesso, operando não como apreensão, mas como revulsão" (ibidem, p. 128).

A dor e angústia, a reboque do sofrimento, consistem na dimensão física que passa pelo corpo na precariedade inerente à condição carnal. Elas compõem a experiência do sofrimento naquilo que se traduz como uma morte material, concreta, e consistem num mal físico em sua intensidade carnal. Dor e angústia são modalidades da encarnação do sofrimento e, por isso mesmo, evidenciam que as contingências e o poder afetam o outro em sua carne, põem em curso, pelo corpo, a obra da morte e a miséria da carne. A real ameaça do sofrimento, porém, não é o temor da morte em seu sentido subjetivo ou filosófico, mas o mal físico que corrói e faz padecer a vida e interrompe um curso. 
O que resta do sofrimento é a "concretude do não" que surge como mal em toda sua negação radical. O sofrimento se apresenta como aquilo que mais se coliga ao humano, isto é, a vulnerabilidade como uma sensibilidade. Por esta dinâmica entre vulnerabilidade e sensibilidade imposta pelo sofrimento como experiência que irrompe e vem ressaltar a assimetria originária da dualidade eu/outro, aqui efetivada pelo par ver/ser visto, é que se depõe a soberania do eu e do sujeito. A equivalência de posições pode reconciliar sujeito e outrem neste processo em que o sofrimento deixa de ser considerado como dado de falência inerente a outrem e passa a ser compreendido como receptividade sensorial para revelar-se no acolhimento do Outro como sujeito.

Esta visão acerca de uma potencialidade especial dos encontros entre imagens e sujeitos não tem a ingenuidade de destacar qualquer ênfase na fotografia, nem como material, nem como prática, tampouco acreditar que haja um poder intrínseco nela que possa, necessariamente, acionar disposições éticas e afetivas de diversas ordens nos sujeitos. A experiência ou a interação a que creditamos uma peculiaridade se dá entre imagem e sujeitos entendidos, também, como corpos, em sua mútua afetação, no âmbito de uma sensibilidade originária, em um movimento do encontro que se realiza.

Na perspectiva de Lévinas, o rosto não se confunde com a representação da face, mas se faz visível a partir do que ele comunica sem se deixar apreender como representação. O rosto, nesse sentido, é diálogo e significação: "é completa exterioridade, inteira relação e comunicação, sinceridade e abertura" (MELO, 2003, p. 89). Para ele, a relação com o rosto não é de conhecimento de um objeto, pois o rosto não se oferece a nós porque o descrevemos. O rosto é por si mesmo e não necessita de um sistema referencial dado por identidades.

Ainda que Lévinas não deseje fazer uma representação do que é o rosto, mas mostrar sua "aparição", ele afirma que o rosto possui uma visibilidade que só é apreendida pelo olhar, na qual o outro que me olha é também o que me revela. O olhar ou, nos termos de Didi-Huberman (2008), a mirada é parte da manifestação e aparição de outrem, além da implicação daquele que olha. Tanto para ele quanto para Rancière não estamos diante das imagens, mas entre elas, e isso requer uma posição: uma implicação na imagem (movimento de apropriação, de conhecimento e, simultaneamente, de auto-constituição) para nos aproximarmos do Outro.

Se o rosto de Lévinas é incapturável pela representação imagética, uma vez que é insubstancial, sua encarnação na face humana não só é possível como ajuda a entender como, por meio do olhar do outro, "o Mesmo é interpelado a abandonar o lugar de quem tudo contempla e sabe" (MELO, 2003, p. 95). Assim, o rosto encarnado na imagem fotojornalística articula três instâncias indissociáveis: o visível, o invisível e o olhar que os coloca em relação.

Será possível conectar o rosto de Lévinas - alteridade extrema - ao rosto da vítima fotografada em seus últimos instantes de vida? A questão não é saber se cabe ou não mostrar os horrores sofridos pelas vítimas desta ou daquela violência simbólica ou física. 
O problema está na construção da "vítima" como elemento de certa distribuição do visível. Para Rancière (2010, p.96), "a imagem é resultado de um dispositivo de visibilidade que regula o estatuto dos corpos representados e o tipo de atenção que merecem. A questão é saber o tipo de atenção que este ou aquele dispositivo provoca." Nesse sentido, o problema relativo a uma política (e uma ética) das imagens se concentra em desvendar qual espécie de senso comum é tecida pela construção desta ou daquela imagem. "É saber que espécie de ser humano a imagem nos mostra e a que espécie de ser humano ela é destinada, que espécie de olhar e de consideração é criada por esta ficção" (idem, 2012, p. 100).

A imagem pode conferir rosto a um indivíduo, tornando-o sujeito a nossos olhos, e, por isso, por permitir sua aparência sob a forma de convocação, faz emergir o lugar da comunicação, da reciprocidade. O rosto de Omayra, capturado pela fotografia, faz do espectador um sujeito ativo na relação, retira-o do lugar daquele que lê códigos, que reconhece sua posição em uma cena dada e que se conforma a um lugar diante do sofredor para deslocá-lo, agitá-lo, inquietá-lo, fazê-lo movimentar-se, participar, aproximarse e distanciar-se pela perturbação e desconforto provocadores. Trata-se de um raro corpo-a-corpo explícito entre aquele que vê e o que se vê no fotojornalismo, pois este corpo não se encontra no lugar da figura legível, mas em sua abertura e contingência.

Angela Cristina Salgueiro Marques é doutora em comunicação social pela UFMG e professora do Programa de Pós-graduação em Comunicação da UFMG.

angelasalgueiro@gmail.com

Angie Biondi é doutora em comunicação social pela UFMG e professora do Programa de Pós-graduação em Comunicação da Universidade Tuiuti do Paraná.

angiebiondina@gmail.com

\section{Referências}

AGAMBEN, G. The face. In: Means without end: notes on politics. Minneapolis: University of Minnesota Press, 2000. p. 91-100.

DELEUZE, G. Espinoza e os signos. Porto: Rés Editora, 1976.

DIDI-HUBERMAN, G. La emoción no dice "yo": diez fragmentos sobre la libertad estética. In: AAVV, Alfredo Jaar. La política de las imágenes. Santiago de Chile: Editorial Metales Pesados, 2008. p.39-67.

O que vemos, o que nos olha. São Paulo: Editora 34, 1998.

. L'image ouverte. Motifs de l'incarnation dans les arts visuels. Paris: Éditions Gallimard, 2007. 
HADDOCK-LOBO, R. A justiça e o rosto do outro em Lévinas. Cadernos EMARF Fenomenologia e Direito. Rio de Janeiro, vol. 3, n.1, set. 2010.

KEHL, M. R. Masculino feminino: o olhar da sedução. In: NOVAES, A. (Org.). O olhar. São Paulo: Companhia das Letras, 1988.

LÉVINAS, E. Entre nós. Ensaios sobre alteridade. São Paulo: Vozes, 2004. . Ética e infinito. Lisboa: Edições 70, 2010.

MELO, N. V. A ética da alteridade em Emmanuel Levinas. Porto Alegre: EDIPUCRS, 2003.

MONDZAIN, M. A imagem pode matar? Lisboa: Nova Vega, 2009.

PICADO, B. A ação e a paixão que se colhem num rosto: pensando os regimes de discurso do retrato humano no fotojornalismo. Revista Galáxia, São Paulo, v. 18, p. 284-299, 2009.

Sobre/pelo/contra o dispositivo: o arché fotográfico revisitado. Revista Matrizes, São Paulo, Ano 4, número 2, p. 165-181, 2011.

POIVERT, M. Crise des usages. In: La photographie contemporaine. Paris: Flammarion, 2010. p.77-120.

RANCIÈRE, J. Le travail de l'image. Multitudes, n.28, 2007, p.195-210.

El teatro de imágenes. In: AAVV, Alfredo Jaar. La política de las imágenes. Santiago de Chile: Editorial Metales Pesados, 2008. p. 69-89.

Política de Pedro Costa. In: Cem Mil Cigarros. Os filmes de Pedro Costa. Lisboa: Orfeu Negro, 2009. p.53-63.

O espectador emancipado. São Paulo: Martins Fontes, 2010.

O destino das imagens. Rio de Janeiro: Contraponto, 2012.

SONTAG, S. Diante da dor dos outros. São Paulo: Companhia das Letras, 2003.

Artigo recebido em abril

e aprovado em outubro de 2015. 